\title{
Developmental Trajectory of Korean Adolescents' Multicultural Receptivity Applying a Latent Growth Model
}

\author{
Sungsim Lee ${ }^{a}$, JuSung Jun ${ }^{b}$
}

\author{
Received \\ Revised \\ Accepted \\ 28 July 2020 \\ 16 February 2021 \\ 23 March 2021 \\ 10.26822 /iejee.2021.206 \\ a Sungsim Lee, Soongsil University \\ E-mail: simi7@nate.com \\ ORCID: https://orcid.org/0000-0002-9812-898X
}

Corresponding author: JuSung Jun, Dept. of Lifelong Education (Chomansik 741), Soongsil University 369 Sangdo-Ro, Dongjak-Gu, Seoul, Korea (06978)

Telephone number: 82-2-10-8001-0094

E-mail:jnet@ssu.ac.kr

ORCID: https://orcid.org/0000-0003-0061-6537

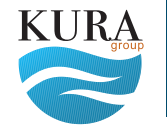

Copyright (c)

WWw.iejee.com

ISSN: 1307-9298

(c) 2021 Published by KURA Education \& Publishing. This is an open access article under the CC BYNC- ND license. (https://creativecommons.org/ licenses/by/4.0/)

\begin{abstract}
The purpose of this study was to analyze the developmental trajectory of Korean adolescents' multicultural receptivity with a latent growth model. The study was performed using the data of 5,943 students (2,918 boys and 3,025 girls) who sincerely responded to all the questions used as variables in the data in the $2^{\text {nd }}, 4^{\text {th }}$, and $6^{\text {th }}$ years of the Korean Education Longitudinal Study: KELS 2013 by the Korean Educational Development Institute. The research results are as follows: First, adolescents' multicultural receptivity insignificantly decreased, as they grew up. Second, peer relations, teacher relations, and community spirit in the early youth influenced the formation of early multicultural receptivity. Third, teacher relations had a positive relationship with multicultural receptivity and affected the change in multicultural receptivity later. Finally, community spirit had a positive relationship with multicultural receptivity, and as time passes, it affects the decrease of adolescents' multicultural receptivity. In conclusion, this study has the significance that it investigated longitudinal changes in multicultural receptivity. The study reviewed and discussed the implications and limitations of the study based on the research results.
\end{abstract}

\section{Keywords:}

Multicultural Receptivity, Community Spirit, Peer Relations, Teacher Relations, KELS, Latent Growth Model

\section{Introduction}

A coording to the immigration statistics by the Korea Aimmigration Service, a Ministry of Justice-affiliated organization (2019), the number of foreigners was 2,367,607 persons in December 2018, 4.57\% of the entire population, which is shown to experience increases each year. The number of multicultural families nationwide in 2018 was 319,000 households, and the number of members of the households was determined to be 964,000 persons. It is expected that the number of multicultural families in this region will reach one million soon (Ministry of Gender Equality \& Family, 2019a). As immigrants entering and staying in the country for various purposes such as jobs, education, marriage and family formation, etc. grow in Korean society, 


\section{iejee}

their numbers of children increase rapidly (Ministry of Gender Equality \& Family, 2019b). For these reasons, the multicultural students in elementary, middle, and high schools were 122,212 persons in 2018, 2.2\% of the entire students, and for the last five years, the number of the entire students has decreased, while that of multicultural students has been shown to have increased (Ministry of Education, 2019). It is noted that the ratio of multicultural students is highest in elementary school, followed by middle and high schools, which is outlined visually in a pyramid shape. This scale is contrasted with the entire school-age population of Korea decreasing. The number of multicultural students will likely increase further to greater numbers in the future (Lee et al., 2017). To coexist and harmonize with members with multicultural backgrounds, it is necessary to change the perspective, perception, attitude, and value of the existing members (Choi, 2014).

In the "2018 Field Survey of Nationwide Multicultural Family" by the Ministry of Gender Equality \& Family (2019a), $8.2 \%$ of children in multicultural families experienced the victimization of school violence, which was similar to the result of the 2012 survey. Thus, it is noted that there has been little change in adolescents' perceptions of multicultural students who are their peers in the school environment. New perceptions of diversity are required as an important quality from adolescents who will lead our society, that will directly experience multicultural society with children in multicultural families (Park, 2014). It is noted that "The 2019 Plan for Education Support for Multicultural Students" announced by the Ministry of Education presents goals, "to construct a mature education environment in which various cultures coexist" and "to secure multicultural students' education opportunities and resolve the education gaps," which emphasizes the harmonious coexistence between multicultural students and general students. With this in mind, it is important for domestic students to improve multicultural receptivity to accept multicultural students with an open mind. Furthermore, it should increase awareness, and recognize them as beings that they should get along with so that students in multicultural families can be well adjusted (Lee, 2015). During adolescence, people form values, and for this reason, it is necessary to form the right values on multicultural society through the right education related to multiculturalism in this period (Cha \& Byeon, 2018).

Looking at the factors affecting adolescents' multicultural receptivity, the factors include personal factors such as the student's sex (Lee, 2015; Oh, Han, \& Yang, 2017; Park, 2014; Roh \& Ha, 2016), and community spirit (Baek \& Chung, 2017; Lee, 2015; Park, 2017; Un, 2016;) and school factors such as peer relations (Baek \& Chung, 2017; Lee, 2015; Un, 2016) and teacher relations (Baek \& Chung, 2017; Park, 2017; Un, 2016). Since Korean adolescents spend much of their time at school, their lives and relationships in school are important to their development. Peers and teachers whom adolescents see and interact with most of the day, often play important roles in the development of their socialization and interpersonal relationship skills (Lee, Lee, \& Han, 2016). Another key point is that of the factors affecting multicultural receptivity, peer relations and teacher relations are important factors for student socialization. These relations are affected by the consciousness of care for others in the student's community spirit as developed by the students in the school environment.

Korean domestic studies of multicultural receptivity were conducted with elementary school students (Choi \& Kim, 2015; Kim \& Hwang, 2012; Lee \& Bang, 2017; Oh, Han, \& Yang, 2017) and analyzed by a review of the variables affecting multicultural receptivity. Since many studies were based on the cross-sectional research design, there is a limitation in inferring the longitudinal causality among the variables. Thus, the purpose of this study was to estimate the developmental trajectory of adolescents' multicultural receptivity, applying a latent growth model. Specifically, this study used the longitudinal data of the 6th graders of elementary schools, $2^{\text {nd }}$-year middle school students, and $1^{\text {st }}$-year high school students of the Korean Education Longitudinal Study 2013 (KELS 2013). In addition, this study would analyze the impacts of adolescents' peer relations, teacher relations, and community spirit on multicultural receptivity. Research questions for this study are as follows.

Research Question 1. Is there a difference in the developmental trajectory of adolescents' multicultural receptivity among individuals?

Research Question 2. What are the impacts of adolescents' peer relations, teacher relations, and community spirit on the developmental trajectory of multicultural receptivity?

\section{Literature review}

\section{Multicultural Receptivity}

In Korean society, studies and academic interests in multicultural receptivity increase awareness of these issues; however, it is defined in various ways by researchers, without consensus, since it is a complex and multidimensional concept (Lee \& Bang, 2017; Lee et al., 2017; Lee, Lee, \& Han, 2016; Park, 2014). Multicultural receptivity is defined as an unbiased, open attitude to foreigners (Kim \& Hwang, 2012). It is also to include awareness, the level of consciousness of accepting the policies related to the realization of multiculturalism aimed by the multicultural society 
(Lee \& Kim, 2012), or an attitude to look at others equal to oneself by recognizing and respecting the fact that others have different skin colors, values, and beliefs as a member of multicultural society (Yang \& Kim, 2015). The Ministry of Gender Equality \& Family (2012) defines multicultural receptivity as an attitude in a comprehensive meaning that one does not have prejudice to members or cultures different from one's group (race and nationality) as a citizen living in a multicultural society. This definition also recognizes the level of receptivity as equally as one's own culture (mutual recognition), whereby a person cooperates and makes an effort to set harmonious relations with them (direction of coexistence), does not grade foreigners or immigrants by their native place or economic level and would practice that based on the universal value as one of the global citizens (Ministry of Gender Equality \& Family, 2012). For this reason, multicultural receptivity is also defined as the ability to understand and accept other's cultures in a multicultural condition (Lee \& Bang, 2017). It can also be seen or conceptualized as the level of support for the coexistence and acceptance of various races, cultures, and languages or positiveness to change into a multicultural society (Hwang \& Jung, 2019). In this way, Park (2019) defines it as the emotional acceptance of foreigners and the acceptance of their universal rights to coexist with dominant demographically identified cultures.

In foreign studies, the term multicultural sensitivity is used in the same context as that of multicultural receptivity. Here it is identified, and it is defined as a personal ability to develop positive emotions about understanding and recognizing cultural differences (Chen \& Starosta, 2000; Tamam \& Krauss, 2017). The definition goes on to also include awareness or the increase of the recognition of cultures different from one's own (Karpinski \& Heinerichs, 2015). In fact, this study would define multicultural receptivity as the recognition of foreigners equally without prejudice, and the pursuit of harmonious relations with multicultural friends.

\section{Peer Relations}

Obiunu (2015) said that adolescents' friendship is an interpersonal relationship of sharing common interests and emotions at a certain level, and it is important for students, which is a supportive relationship that becomes the resource for the period and the later period of the development stage. Uslu and Gizir (2017) called peer receptivity as peer relations, which is defined as an important aspect of a sense of belonging to the school as is the student's academic and social capabilities. In Korea, peer relations are defined as one's attitude toward their peers. These relations typically include facets related to the communal life, intimate communication, goodwill, and support, and are trusted as well as a reliable friend's duty (Yang, 2019). Song and Lee (2011) define it as a human relationship that children and adolescents have with their peers during development. In this study, peer relationships are defined as respected, understood, and trusted relationships with peers.

\section{Teacher Relations}

The relationship between the teacher and students provides the resources so they can become independent members of society. These students benefit from this relationship through the adjustment to school life and smooth interpersonal relations, as well as their academic aspect in the continuous process of exchange (Kim et al., 2019). Agrawal et al. (2019) noted that a good relationship between the teacher and the students is a safe, satisfying, and supportive relationship. Primarily it is a positive relationship development for students, which improves academic achievement and reduces the incidence of the student's problem behaviors. Teacher relations are psychological space provided by teachers for students. These teacher relations are also positive, and are defined as an area in which their behaviors or thoughts can be supported by sharing such psychological space with students (Kim \& Kim, 2014). This process is also described as a type of interaction between the teacher and the students with the social environment of the school as the background (Lee \& Han, 2017). This study would define teacher relations as the positive support for students from teachers based on the questions of KELS.

\section{Community Spirit}

Jones and Davenport (2018) defined community spirit as various structures with social and psychological elements. Moreover, it is noted that in the school environment, community spirit is an element contributing to the positive school atmosphere. It is important to realize that the idea of community spirit is a state in which one maintains meaningful relationships with members in the community one belongs to and has the senses of closeness, belonging, and kinship (Han \& Oh, 2013). Additionally, community spirit may serve as a facilitator for accepting various cultures and races by allowing students to make meaningful relationships with school or peer groups. The enhancement students receive from developing relations with peer groups is positive, and encourages feelings of a sense of belonging, a sense of kinship, and a sense of closeness (Yang \& Gwon, 2018). In this way, community spirit is a concept that recognizes the diversity of individuals and emphasizes life as a community based on communitarianism (Baek \& Chung, 2017). This study would define community spirit as attention and a sense of belonging to the community one belongs to and an intention to 


\section{iejee $\approx$}

participate in the parts one can do, in order that the individual's participation can enhance the chance at the development of a better community.

\section{Correlations of Multicultural Receptivity with Peer Relations, Teacher Relations, and Community Spirit}

To examine the preceding studies related to multicultural receptivity, studies were reporting that the better peer relations, the higher multicultural receptivity became (Baek \& Chung, 2017; Un, 2016; Lee, 2015). Additionally, there was also data and studies reporting that the better teacher relations, the higher multicultural receptivity became (Park, 2017; Baek \& Chung, 2017; Un, 2016). In Kim (2019), which was a longitudinal study of adolescents' social relations and multicultural receptivity, peer relations and teacher relations had significant impacts on multicultural receptivity. This result was also shown in Roh and $\mathrm{Ha}$ (2016), which investigated a longitudinal change in adolescents' multicultural receptivity, peer relations, teacher relations, and community spirit were shown to have affected multicultural receptivity. There is a study reporting that in the relationship of the impact between multicultural receptivity and community spirit, positive multicultural receptivity formed in a previous time had a significant impact only on the promotion of community spirit (Lee, 2015), a study reporting that the group in which multicultural receptivity increases longitudinally also shows a longitudinal increase in community spirit (Baek \& Chung, 2017) and studies reporting that multicultural receptivity affects community spirit (Park, 2014; Un, 2016).

\section{Methods}

\section{Subjects}

This study was conducted, using the partial data necessary for the study in the $2^{\text {nd }}$ year $(2014), 4^{\text {th }}$ year (2016), and $6^{\text {th }}$ year (2018) of data in the Korean Education Longitudinal Study (KELS 2013). The KELS 2013 data was collected from $5^{\text {th }}$ graders of elementary school nationwide each year from 2013 through 2018 by the Korean Educational Development Institute. The KELS 2013 data is a longitudinal study at a national level. It was constructed of 7,324 $5^{\text {th }}$ grade elementary school students as a sample panel in 2013 and investigated them every year for the 6 years until 2018 (Korean Educational Development Institute, 2018). The research subjects of this study were 5,943 persons who faithfully responded to all the questions used as variables, 2,918 boys (49.1\%) and 3,025 girls (50.9\%).

\section{Measurement Tools}

This study would deal with four variables, one dependent variable (multicultural receptivity) and three independent variables (peer relations, teacher relations, and community spirit). For the questions of multicultural receptivity, this study used those in "the Global Leading School Student Life Opinion Survey" conducted in December 2012 by the Center for Multicultural Education Research of Seoul National University of Education used in KELS 2013. On the whole, the multicultural receptivity consists of five questions about the perceptions of foreigners and six questions about the relationships with multicultural neighbors/friends. Additionally, the measurements were made on a 5 -point Likert scale, and two of five questions about the perceptions of foreigners are reverse-scored ones.

For teacher relations, this study used the six questions modified from the teachers in charge in the questions of KELS 2005 to school teachers in KELS 2013. When reviewing peer relations, the questions utilizing the related six questions in the "Korean Children and Adolescents Panel Survey" used in KELS 2013 were used. For community spirit, the questions were the ones the same as those in KELS 2005 used in KELS 2013. As an illustration, the survey in 2014 consisted of the two factors of consciousness of participation and care for others. This is contrasted with the survey in 2016 and 2018 which also consisted of three factors, which were the consciousness of participation, civic consciousness, and cooperative behavior. This study used a total of six questions, the consciousness of participation (two questions) and care for others (four questions), which were surveyed in all $2^{\text {nd }}, 4^{\text {th }}$, and $6^{\text {th }}$ years. The composition and scale of the variables used in this study and the internal consistency among the questions (Cronbach $\alpha$ ) are like Table 1 below.

\section{Table 1.}

The Cronbach a of the Variable

\begin{tabular}{lr}
\hline Variables & Cronbach a \\
\hline Peer relations & .910 \\
Teacher relations & .930 \\
Community spirit & .855 \\
$6^{\text {th }}$ grade of elementary school multicultural & .856 \\
receptivity & .873 \\
$2^{\text {nd }}$ year of middle school multicultural recep- & .872 \\
tivity & \\
$1^{\text {st }}$ year of high school multicultural receptivity & \\
\hline
\end{tabular}

\section{Analysis Method}

This study would calculate the descriptive statistics of the measurement variables, using SPSS 25 with the relevant materials of the data in KELS 2013. Particularly, the study works to estimate the change in adolescents' multicultural receptivity, and conduct an analysis, using the 'latent growth model (LGM)' method used to account for the difference in the change among 
individuals. The LGM method is a method to analyze the size of the change, using longitudinal data or panel data measured at least three times (Heo, 2013). By applying a linear model, the factor loading of intercept of multicultural receptivity is fixed to 1 and the factor loading of slope is set to 0,1 , and 2 from the first year through the third year. Figure 1 and Figure 2 show a structural model indicating the relevance of changes in each variable. Using AMOS 22, the first step is to verify the growth model without inputting predictive variables into the model, and the second step is to set and analyze the conditional model by inputting peer relations, teacher relations, and community spirit as predictive variables.

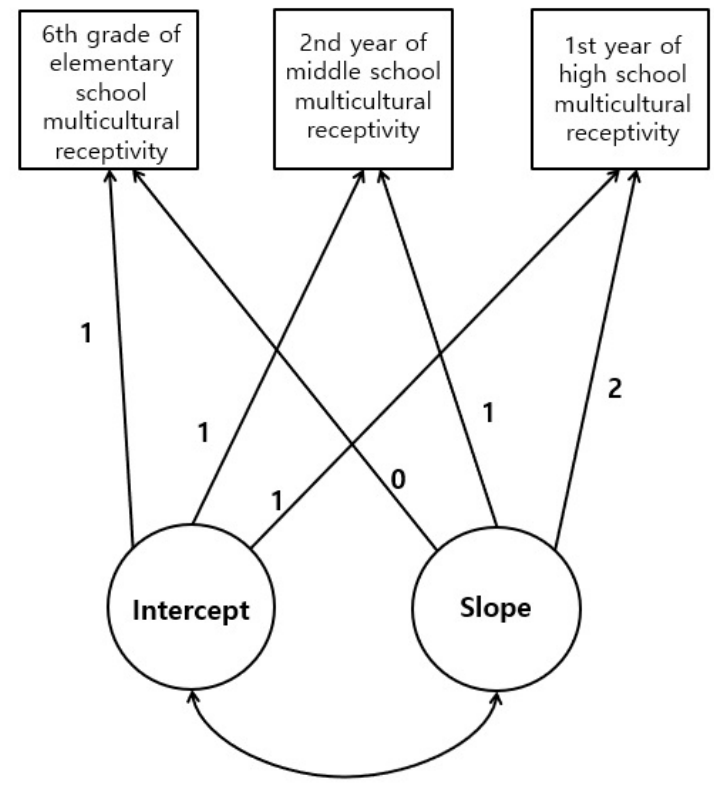

Figure 1.

Analysis multicultural receptivity: Unconditional model

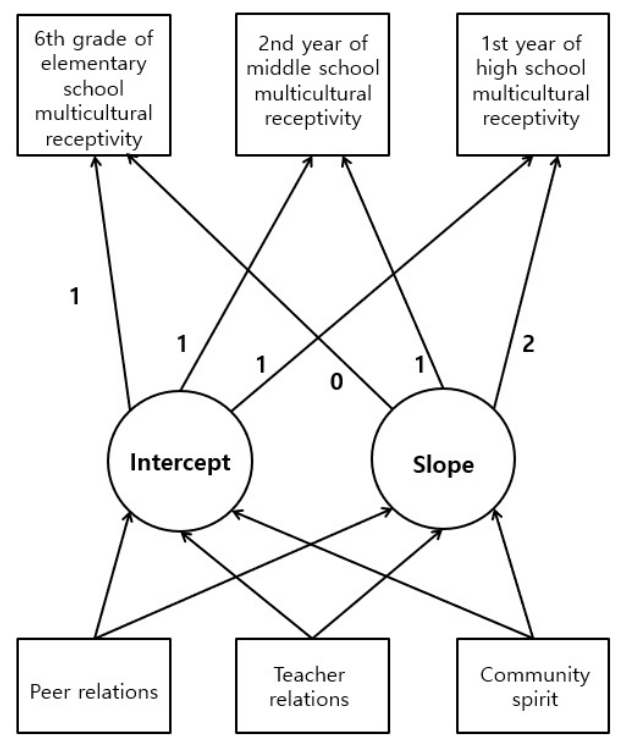

Figure 2.

Analysis multicultural receptivity: Conditional model

\section{Results}

Descriptive Statistics and Correlations of the Measurement Variables

This study found the descriptive statistics of the measurement variables of adolescents' peer relations, teacher relations, community spirit, and multicultural receptivity (See Table 2). As a result of the measurement, that identified the noted skewness was between -.488 and -.055 , and kurtosis was between -.422 and .194, which met the criteria for normal distribution. With this in mind, the mean score of adolescents' multicultural receptivity decreased from 4.193 in the $6^{\text {th }}$ grade of elementary school to 4.154 in the 2 nd year of middle school and 4.130 in the $1^{\text {st }}$ year of high school. As time passed, there was a decreasing tendency of adolescents' multicultural receptivity. As a result of an analysis of the correlations among the variables through correlation analysis, all the measurement variables had significant correlations at $p=.01$ (See Table 3).

\section{Unconditional Model of Adolescents' Multicultural Receptivity}

This study estimated change in multicultural receptivity with an unconditional model, without putting in predictors to estimate the adolescents' developmental trajectory of multicultural receptivity. As noted in Figure 3, Intercept and slope were set at potential variables, and the path coefficient from intercept to the measurement variable was set to 1 , and slope was set to 0,1 , and 2 to set a linear change model.

The goodness-of-fit values of the linear change model were $\mathrm{TLI}=.980, \mathrm{CFI}=.980$, and RMSEA $=.064$. It was a good model for the goodness-of-fit criterion (See Table 4). Table 5 shows the estimates of the mean and variance of intercept and slope. In this case, the mean of intercept was 4.191 ( $p<.001)$, and the variance was 166 ( $p<$. 001). There was a significant difference in the intercept of multicultural receptivity among adolescents. For slope, the mean was -.031 $(p<.001)$. There was a statistically significant gradual decreasing tendency of multicultural receptivity during adolescence, and the variance of slope was $.024(p<.001)$. Related to this data there is a significant difference in the trajectory of change in adolescents' multicultural receptivity among individuals. The covariance between intercept and slope was -.018 ( $p<.001)$, which was a significant negative covariance. This shows that adolescents with high multicultural receptivity in the $6^{\text {th }}$ grade of elementary school, have a slow decrease in the level of multicultural receptivity as they get older. 
Table 2.

Descriptive Statistics $(N=5943)$

\begin{tabular}{|c|c|c|c|c|}
\hline Variables & M & SD & Skewness & Kurtosis \\
\hline $6^{\text {th }}$ grade of elementary school multicultural receptivity & 4.193 & .559 & -.413 & -.422 \\
\hline $2^{\text {nd }}$ year of middle school multicultural receptivity & 4.154 & .571 & -.372 & -.203 \\
\hline $1^{\text {st }}$ year of high school multicultural receptivity & 4.130 & .565 & -.401 & .003 \\
\hline $6^{\text {th }}$ grade of elementary school peer relations & 3.956 & .765 & -.488 & .012 \\
\hline $6^{\text {th }}$ grade of elementary school teacher relations & 3.879 & .806 & -.459 & .194 \\
\hline $6^{\text {th }}$ grade of elementary school community spirit & 3.877 & .638 & -.055 & -.323 \\
\hline
\end{tabular}

Table 3.

Correlations among the Measurement Variables

\begin{tabular}{|c|c|c|c|c|c|c|}
\hline & 1 & 2 & 3 & 4 & 5 & 6 \\
\hline 1. $6^{\text {th }}$ grade of elementary school multicultural receptivity & 1 & & & & & \\
\hline 2. $2^{\text {nd }}$ year of middle school multicultural receptivity & $.457^{* *}$ & 1 & & & & \\
\hline 3. $1^{\text {st }}$ year of high school multicultural receptivity & $.375^{* *}$ & $.536^{* *}$ & 1 & & & \\
\hline 4. $6^{\text {th }}$ grade of elementary school peer relations & $.349^{* *}$ & $.235^{* *}$ & $.224^{* *}$ & 1 & & \\
\hline 5. $6^{\text {th }}$ grade of elementary school teacher relations & $.367^{* *}$ & $.213^{* *}$ & $.207^{* *}$ & $.461^{* *}$ & 1 & \\
\hline 6. $6^{\text {th }}$ grade of elementary school community spirit & $.557^{* *}$ & $.305^{* *}$ & $.273^{* *}$ & $.485^{* *}$ & $.456^{* *}$ & 1 \\
\hline
\end{tabular}

${ }^{* *} p<.01$

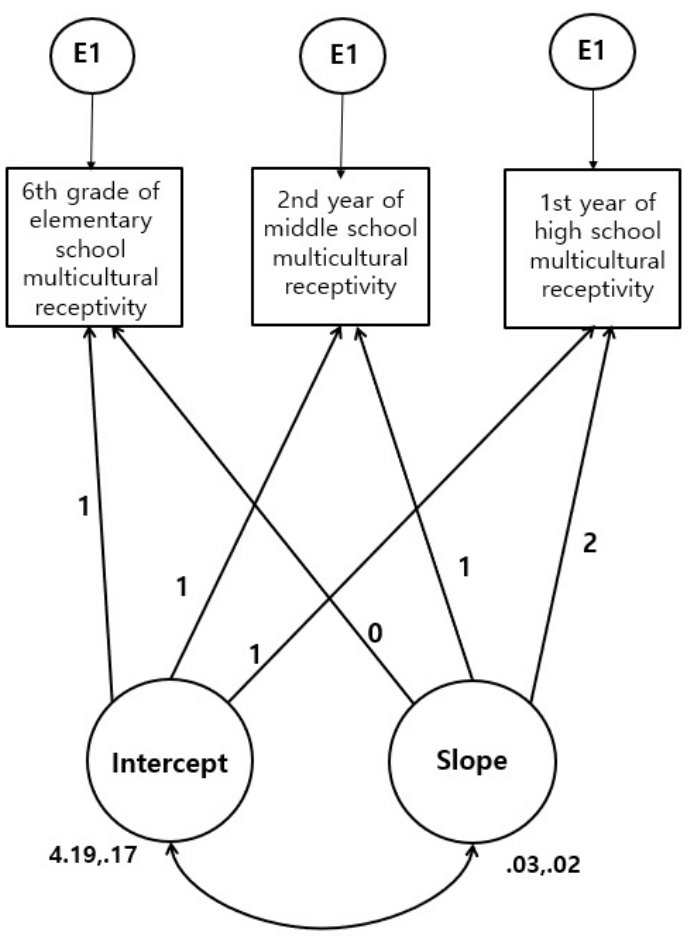

Figure 3.

Mean and variance estimates of the intercept and slopes
Table 4.

Goodness-of-fit Index of the Unconditional Model

\begin{tabular}{lrrrrrr}
\hline & $\chi^{2}$ & $d f$ & $p$ & TLI & CFI & RMSEA \\
\hline $\begin{array}{l}\text { Unconditional } \\
\text { model }\end{array}$ & 75.802 & 3 & .000 & .980 & .980 & .064 \\
\hline
\end{tabular}

Table 5.

Intercept and Slope of the Unconditional Model

\begin{tabular}{lcc}
\hline & Mean & Variance \\
\hline Intercept & $4.191^{\cdots *}$ & $.166^{\cdots *}$ \\
Slope & $-.031^{\cdots *}$ & $.024^{\cdots}$ \\
Covariance & $-.018^{\cdots *}$ & \\
\hline
\end{tabular}

${ }^{* * *} p<.001$

Impacts of Adolescents' Peer Relations, Teacher Relations, and Community Spirit on the Developmental Trajectory of Multicultural Receptivity

This study set peer relations, teacher relations, and community spirit as the factors affecting the developmental trajectory of adolescents' multicultural re- 
ceptivity. The paths of intercept and slope were set by putting the predictors into an unconditional model.

The goodness-of-fit values of the conditional model were $\mathrm{TLI}=.942, \mathrm{CFI}=.973$, and RMSEA $=.079$. It was also a good model for the goodness-of-fit criterion (See Table 6). In Table 7, adolescents' peer relations had a significant impact on the intercept of multicultural receptivity $(\beta=.093, p<.001)$. In other words, the higher their peer relations, the higher the intercept of multicultural receptivity in that case. Naturally, it was shown that the teacher relations had a positive impact on the intercept of multicultural receptivity $(\beta=.150, p<.001)$, while it had a significant negative impact on slope in multicultural receptivity $(\beta=-.078, p<.01)$. In other words, the students who have high teacher relations in the 6th grade of elementary school have a high intercept of multicultural receptivity and have a slow decrease in multicultural receptivity. In this case, the adolescents' community spirit had a positive impact on the intercept of multicultural receptivity $(\beta=.588$, $p<.001$ ). Even though it had a significant negative impact on slope in multicultural receptivity $(\beta=-.467$, $p<$.001). In other words, the students who have high community spirit in the $6^{\text {th }}$ grade of elementary school have a high intercept of multicultural receptivity and have a slow decrease in multicultural receptivity.

\section{Table 6.}

Goodness-of-fit Index of the Conditional Model

\begin{tabular}{lrrrrrr}
\hline & $\chi^{2}$ & $d f$ & $p$ & TLI & CFI & RMSEA \\
\hline $\begin{array}{l}\text { Conditional } \\
\text { model }\end{array}$ & 269.461 & 7 & .000 & .942 & .973 & .079 \\
\hline
\end{tabular}

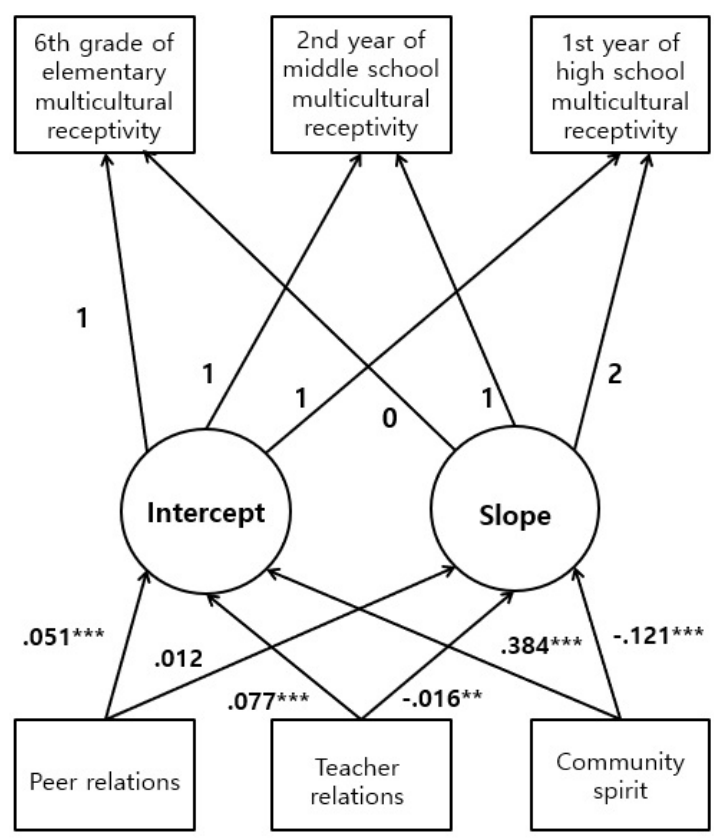

Figure 4.

Conditional model of multicultural receptivity (Non-standardized coefficient)

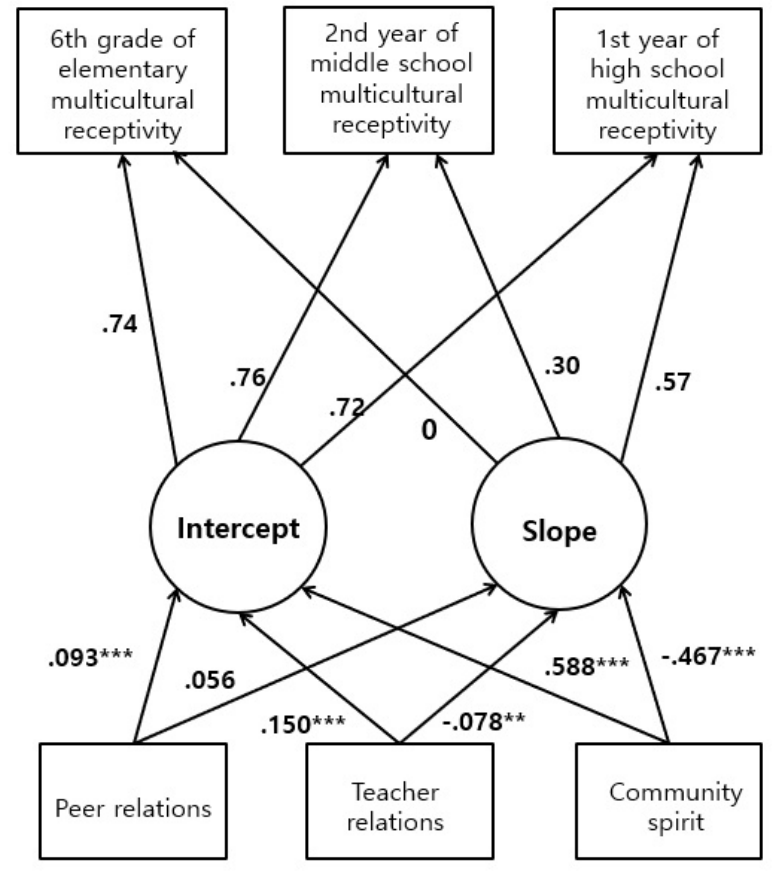

Figure 5.

Conditional model of multicultural receptivity (Standardized coefficient)

\section{Discussions and Conclusions}

The purpose of this study was to analyze the impacts of adolescents' peer relations, teacher relations, and community spirit on the longitudinal change in their multicultural receptivity. For this purpose, this study investigated the latent growth model, utilizing the data of the $2^{\text {nd }}$ year (2014), the $4^{\text {th }}$ year $(2016)$, and the $6^{\text {th }}$ year (2018) in the KELS 2013 Panel. The discussions according to the main results of this study are as follows:

First, the developmental trajectory of adolescents' multicultural receptivity gradually decreased as time passed from $6^{\text {th }}$ grade in elementary school through $2^{\text {nd }}$ grade in middle school to $1^{\text {st }}$ grade in high school. This result is different from Yang and Gwon's (2018) research, which was a longitudinal study with middle school students, in which the mean of multicultural receptivity increased as they advanced into a higher grade. And yet, it is shown that this is the same result as that of Oh, Han, and Yang (2017), a study with elementary and middle school students, where multicultural receptivity was higher in elementary school students than in middle school students. Jeon and Chung (2017) analyzed potential groups from the $5^{\text {th }}$ grade of elementary school through the $3^{\text {rd }}$ year of middle school. In that study, it is noted that there is a group in which multicultural receptivity increases while there is a group in which it decreases as time passes. 
Table 7.

Path Coefficient of the Conditional Model

\begin{tabular}{|c|c|c|c|c|c|}
\hline Path & $\mathrm{B}$ & $\beta$ & S.E. & C.R. & $p$ \\
\hline Peer relations $\rightarrow$ multicultural receptivity intercept & .051 & .093 & .009 & 5.488 & .000 \\
\hline Peer relations $\rightarrow$ multicultural receptivity slope & .012 & .056 & .006 & 1.931 & .053 \\
\hline Teacher relations $\rightarrow$ multicultural receptivity intercept & .077 & .150 & .009 & 8.978 & .000 \\
\hline Teacher relations $\rightarrow$ multicultural receptivity slope & -.016 & -.078 & .006 & -2.756 & .002 \\
\hline Community spirit $\rightarrow$ multicultural receptivity intercept & .384 & .588 & .011 & 34.785 & .000 \\
\hline Community spirit $\rightarrow$ multicultural receptivity slope & -.121 & -.467 & .007 & -16.179 & .000 \\
\hline
\end{tabular}

Second, as a result of an analysis of the unconditional model of adolescents' multicultural receptivity, there were significant differences in the variance of intercept and slope. It shows that there is a difference in the development trajectory of multicultural receptivity among individuals. The element of slope is one that shows that there is a difference in developmental trajectory among individuals. For one thing, the development pattern of multicultural receptivity from the $6^{\text {th }}$ grade of elementary school through the $3^{\text {rd }}$ year of high school is not the same. In this case, the developmental trajectory may differ depending on the predictors. This result is the same as that of Kim (2019), where intercept of multicultural receptivity and slope were statistically significant from the $2^{\text {nd }}$ year of middle school through the $3^{\text {rd }}$ year of high school.

Third, as a result of an analysis of a conditional model in which peer relations, teacher relations, and community spirit were put in as predictors, peer relations, teacher relations, and community spirit were all the factors predicting intercept of multicultural receptivity. In the $6^{\text {th }}$ grade of elementary school, early adolescence, peer relations, teacher relations, and community spirit affected the formation of multicultural receptivity. It must be remembered that this is the same as the results of Roh and $\mathrm{Ha}$ (2016) and Park (2014), where peer relations, teacher relations, and community spirit affect intercept of multicultural receptivity.

Finally, it is noted that the incidence of teacher relations and community spirit have significant impacts on slope in multicultural receptivity. This is different from Kim's (2019), where peer relations have a significant impact on slope in multicultural receptivity, while it is the same as the result that teacher relations affect slope. In addition, this result is the same as that of Cha and Byeon (2018). Cha and Byeon were a study that identified teacher relations and community spirit as the factors having the greatest impact on multicultural receptivity in Korean adolescents in middle and high school, which is seen through an analysis of the preceding studies.
The suggestions and conclusions presented based on the main results as above are as follows.

First, this study longitudinally analyzed how the longitudinal change of adolescents' multicultural receptivity and how peer relations, teacher relations, and community spirit in the early adolescence had an effect on multicultural receptivity. In its most positive context, peer relations during early adolescence had a positive relationship with multicultural receptivity. In this case, making good relationships with peers during early adolescence has a positive impact on adolescents' multicultural receptivity. To increase multicultural receptivity, peer relations in school, where adolescents make social relationships during early adolescence are important. It is noted that for this purpose, schools should be able to develop programs and provide activities in order that they can make positive peer relations during early adolescence.

Second, teacher relations had a positive effect on the early stage of multicultural receptivity and have a lasting effect on the change of adolescents' multicultural receptivity later. It is shown that having good teacher relations during early adolescence has a positive impact on adolescents' multicultural receptivity. To increase adolescents' multicultural receptivity, teachers should treat all students with attention and affection without exhibiting any prejudice to any one group of students. Since the teacher's values can be delivered to students when the students have a good relationship with the teacher, the teachers, too, should first have the right understanding, knowledge, and attitude toward "multicultural" students. In this way, it is necessary to increase their multicultural receptivity as well. To do so, it is necessary to develop and provide programs for the promotion of their multicultural receptivity that would be available and apply to all students equally.

Finally, community spirit had a positive relationship with multicultural receptivity, and as time passes, it affects the decrease of adolescents' multicultural receptivity. In addition, in the standardized path coefficient in this study, the figure of community spirit is the 
largest as noted in the data. For this reason, therefore, its influence on multicultural receptivity may as well be exhibited greatly. During adolescence, it is necessary to systematically conduct education that allows students to serve as members of society. It is also important for the students to have a community spirit with which they can coexist in a multicultural society, instead of the education of knowledge focused on the college entrance exam (Park, 2017). To this end, it is necessary to establish personality education and multicultural education that can develop a capacity for other cultures and races, not education that focuses only on changes to a multicultural society.

This study has the significance that it examined the developmental trajectory of the multicultural receptivity of adolescents in elementary, middle and, high school, utilizing the data of KELS 2013. In this case, it analyzed that the data regarding the development of adolescents was significant, by putting in the predictors affecting that the factors related to information, including peer relations, teacher relations, and community spirit. The Ministry of Education (2019) presents "students are growing up, learning together and diverse and harmonious school" as the vision of multicultural education. For this reason, it is important to seek a way to fulfill the vision of multicultural education, and in this way, the results of this study can be utilized as an example of these principles. And yet, since this study was conducted only with the data of the Korean Educational Development Institute, it has a limitation. This limitation is that it did not include all of the factors related to various adolescents' actual developmental conditions. In addition, since this study was conducted with the general students, it would be necessary to conduct a study in the future with multicultural students who urgently need practical help.

\section{References}

Agrawal, D. C., Hou, H. Y., Cheng, T. M., Chen, L. S., \& Hsu, S. C. (2019). Factors affecting studentteacher relationship in a private university of technology in Taiwan. Journal of Institutional Research South East Asia, 17(1), 54-76.

Baek, S., \& Chung, H. (2017). The developmental trajectories of multicultural acceptance and the changing community spirit as determined by means of growth mixture modeling. Studies on Korean Youth, 28(1), 151-182.

Cha, S., \& Byeon, H. (2018). A systematic review on factors influencing multicultural acceptance in Korean adolescents. Journal of the Korea Academia-Industrial Cooperation Society, 19(7), 207-213.
Chen, G. M., \& Starosta, W. J. (2000). The development and validation of the intercultural communication sensitivity scale. Human Communication, 3, 1-15.

Choi, J. Y., \& Kim, J. C. (2015). Exploration of psychological and social factors that influence multicultural acceptance for elementary students. Korean Journal of Youth Studies, 22(2), 389-411.

Choi, M. S. (2014). An analysis of differences and effect factors in multicultural acceptability between teachers and adolescents (Unpublished doctoral dissertation). Donga University, Busan, Korea.

Han, D. D., \& Oh, K. H. (2013). The effects of the communal classroom instructional practices and the sense of community on the inhibitory school violence in elementary schools. Korean Journal of Sociology of Education, 23(4), 207235.

Heo, J. (2013). Easily following AMOS structural equation modeling of Jun Heo: Advanced. Seoul: Hannarae Publishing.

Hwang, C. H., \& Jung, S. H. (2019). A study on the perceptions of foreign immigrants and factors influencing multicultural acceptance. The Journal of Convergence Society and Public Policy, 23(4), 207-235.

Jeon, H. J., \& Chung, H. W. (2017). Relationship between the latent class of community spirit and multicultural acceptance using the sequential process growth mixture model. Journal of Learner-Centered Curriculum and Instruction, 17(9), 335-360.

Jones, P. W. G., \& Davenport, E. K. (2018). A sense of community among educators at predominantly African American high schools. The Journal of Negro Education, 87(3), 338-349.

Karpinski, C., \& Heinerichs, S. (2015). Exploring the effect of a speaker series has on students' level of multicultural sensitivity and cultural competence awareness. The Internet Journal of Allied Health Sciences and Practice, 13(3), 1-5.

Kim, D. J. (2019). The effects of adolescents' social relationships on multicultural acceptance: A longitudinal analysis using latent growth curve modeling. Theory and Research in Citizenship Education, 51(1), 1-26. 


\section{iejee $\approx$}

Kim, J. B., \& Kim, J. Y. (2014). Effects of perceptual differences in student-teacher relationships between student and teacher on the level of understanding instructions: Relating with teachers' job satisfaction and students' peer and parental trust. Journal of Korean Education, 31(3), 245-267.

Kim, K. K., \& Hwang, Y. J. (2012). Determinants of multicultural acceptability of elementary and secondary school students. Journal of Korean Education, 39(1), 87-117.

Kim. J. W., Kang, H. S., Chea, H. W., Sohn, D., \& Song, S. I. (2019). A study of variables affecting middle school students' relationships with teachers and peers. Korean Journal of Educational Administration, 37(1), 171-196.

Korea Immigration Service (2019). Immigration statistics in 2018. Retrieved from http://www.immigration. go.kr/

Korean Educational Development Institute (2018). 2018 Korean Education Longitudinal StudyKorean Education Longitudinal Study 2013(VI): Investigation Summary Report. Korean Educational Development Institute.

Lee, E. B., \& Han, C. K. (2017). The effect of adolescents' relationship with teachers on intrinsic life goalsfocusing on the mediation effect of self-esteem. Journal of the Korean Society of Child Welfare, (59), 87-114.

Lee, H. S., Chung, J. Y., Jang, S. Y., Jang, S., \& Kim, J. (2017). An analysis of factors affecting elementary school students' levels of multicultural acceptance. Studies on Korean Youth, 28(2), 225-248

Lee, J. H. \& Kim, K. K. (2012). Determinants of Koreans' multicultural acceptability: Focusing on the effect of educational attainment. Korean Journal of Sociology of Education, 22(3), 163-192.

Lee, S. A., \& Bang, G. H. (2017). An influence on multicultural acceptability according to student's multicultural understanding and attitude in elementary schools. Journal of Learner-Centered Curriculum and Instruction, $17(17), 837-856$.

Lee, S. K. (2015). Longitudinal changes and determinants of adolescents' acceptability toward multiculture. Korean Journal of Youth Studies, 22(10), 27-48.
Lee, T. H., Lee, S. Y., \& Han, Y. S. (2016). Analysis of the association between teacher relationship, peer relationship, and multicultural acceptability among adolescents in Korea: Using latent growth modeling. The Korean Journal of Culture and Social Issues, 22(1), 65-85.

Ministry of Education (2019). 2019 Multicultural education support plan. Retrieved from http:// www.moe.go.kr/

Ministry of Gender Equality and Family (2012). Research on national multicultural acceptance. Retrieved from http://www.mogef.go.kr/

Ministry of Gender Equality and Family (2019a). 2018 field survey of nationwide multicultural family. Retrieved from http://www.mogef.go.kr/

Ministry of Gender Equality and Family (2019b). Research on national multicultural acceptance in 2018. Retrieved from http://www.mogef.go.kr/

Obiunu, J. J. (2015). Relationship between parents and peer influences on qualities of adolescent friendship. Journal of Education and Practice, 6(8), 128-133.

Oh, S. A., Han, Y. K., \& Yang, Y. E. (2017). An analysis of the effects on multicultural acceptability of primary and secondary school students: Evidence from students whose schools with exchanged foreigner teachers. Korean Journal of Educational Administration, 35(4), 1-22.

Park, S. H. (2014). A longitudinal analysis on multicultural perception of young people using latent growth model. Multicultural Studies, 3(2), 99-131.

Park. A. S. (2017). Ecosystemic factors that affect the multicultural receptivity of the youth. Journal of the Korean society for Wellness, 12(1), 93-106.

Park. S. (2019). The relationship between national identity, threat awareness, and multi-cultural acceptability: Moderating effect of living in ethnic places. Journal of the Korean Regional Science Association, 35(1), 19-31.

Roh, J., \&Ha, J.K. (2016). The factor of longitudinal change in adolescents' multicultural acceptance: The use of latent growth modeling. Journal of MultiCultural Contents Studies, 21, 243-270.

Song, Y. M., \& Lee, H. C. (2011). The determinants of friendship among adolescent in Korea. The Journal of Korean Teacher Education, 28(1), 91112. 
Tamam, E., \& Krauss, S. E. (2017). Ethnic-related diversity engagement differences in intercultural sensitivity among Malaysian undergraduate students. International Journal of Adolescence and Youth, 22(2), 137-150.

Un, S. K. (2016). A study on factors influencing on adolescents' multicultural acceptability: Compared elementary school student and middle school students. Journal of the Korea Academia-Industrial Cooperation Society, 17(10), 685-695.

Uslu, F., \& Gizir, S. (2017). School belonging of adolescents: The role of teacher-student relationships, peer relationships and family involvement. Educational Sciences: Theory and Practice, 17(1), 63-82.

Yang, M. H., \& Gwon, S. A. (2018). A longitudinal analysis using latent growth curve modeling on the middle school students' self-concept, community spirit, \& multicultural acceptance. Journal of 12th Korean Educational Longitudinal Study Conference, 189-208.

Yang, S. H. (2019). The effect of college festival participants experience on festival satisfaction, re-participation and peer relation enhancement: Focusing on college life participation. Journal of Korea Contents Association, 19(7), 246-257.

Yang, Y. M., \& Kim, J. S. (2015). Relationship between children's self-esteem, sense of community, and multicultural receptivity. Journal of Youth Welfare, 17(4), 309-328. 